NBER WORKING PAPER SERIES

\title{
MONITORING AND ENFORCEMENT OF CLIMATE POLICY
}

\author{
Hilary Sigman \\ Working Paper 16121 \\ http://www.nber.org/papers/w16121 \\ NATIONAL BUREAU OF ECONOMIC RESEARCH \\ 1050 Massachusetts Avenue \\ Cambridge, MA 02138 \\ June 2010
}

I am grateful to Severin Borenstein, Howard Chang, Don Fullerton, and participants at the NBER conference for helpful comments. The views expressed herein are those of the author and do not necessarily reflect the views of the National Bureau of Economic Research.

NBER working papers are circulated for discussion and comment purposes. They have not been peerreviewed or been subject to the review by the NBER Board of Directors that accompanies official NBER publications.

(C) 2010 by Hilary Sigman. All rights reserved. Short sections of text, not to exceed two paragraphs, may be quoted without explicit permission provided that full credit, including $\bigcirc$ notice, is given to the source. 
Monitoring and Enforcement of Climate Policy

Hilary Sigman

NBER Working Paper No. 16121

June 2010, Revised September 2010

JEL No. K42,Q54,Q58

\begin{abstract}
$\underline{\text { ABSTRACT }}$
This chapter applies recent research on environmental enforcement to a potential U.S. program to control greenhouse gases, especially through emission trading. Climate policies present the novel problem of integrating emissions reductions that are relatively easy to monitor (such as carbon dioxide emissions from fossil fuels) with those that may be very difficult to monitor (such as some emissions of other greenhouse gases). The paper documents the heterogeneity in monitoring costs across different parts of current carbon markets. It argues that a broad emission trading system that includes more difficult-to-enforce components can provide less incentive to violate the law than a narrower program; thus, the government may not find it more costly to assure compliance with a broader program.
\end{abstract}

Hilary Sigman

Department of Economics

Rutgers University

75 Hamilton Street

New Brunswick, NJ 08901-1248

and NBER

sigman@econ.rutgers.edu 
Effective enforcement is critical to a successful climate policy. ${ }^{1}$ Fortunately, many of the central elements of a climate policy may be easy to enforce transparently and with moderate transaction costs. However, enforcement of other aspects of climate policy can be daunting. Enforcement is sometimes a dominant consideration in the design of responses to greenhouse gases other than carbon dioxide and to carbon dioxide from sources other than fossil fuels.

As a consequence, climate policy poses the novel challenge of integrating easy-to-enforce and difficult-to-enforce components in one policy. In this chapter, I discuss this issue and present some data from existing carbon markets on the disparities in ease of monitoring and enforcement. Empirically, monitoring costs differ considerably across compliance methods.

These differences in monitoring costs may be viewed as a reason to restrict allowance trading to easily monitored activities. In the standard model of environmental enforcement, however, the incentive to comply depends on the allowance price. Thus, this chapter argues that expanding markets to include more difficult to enforce emissions sources may not lower compliance; lower allowance prices in broader markets decrease the incentive to violate the policy.

\section{Incentives for compliance with a climate policy}

In this section, I present a basic model of enforcement of incentive-based environmental policy that has been used extensively in the prior literature (e.g., Harford, 1978; Stranlund and Dhanda, 1999; Stranlund et al. 2002). The model yields one simple insight that I rely on to analyze practical enforcement issues in the rest of the chapter.

\footnotetext{
${ }^{1} \mathrm{~A}$ few recent papers address the economics of the enforcement of climate policies specifically (Kruger and Pizer, 2004; Johnstone, 2005; Kruger and Engenhofer, 2006).
} 


\subsection{The compliance decision}

The standard environmental enforcement model considers a risk-neutral emitter who seeks to minimize the sum of compliance cost plus the expected punishment. ${ }^{2}$

Compliance costs depend on the form of the public policy. With a performance standard, compliance costs are just the costs of reducing emissions, $c\left(e_{i}, \gamma_{i}\right)$, where $e_{i}$ is the emission level of emitter $i$ and $\gamma_{i}$ reflects cost heterogeneity across the emitters. An incentive-based policy adds to the compliance cost a term that reflects net outlays (purchases or sales) of allowances or tax paid on emissions. Under a cap-and-trade program, an emitter with initial allowance allocation of $Q_{i}$ thus has a compliance cost of $c\left(e_{i}, \gamma_{i}\right)+p \times\left(q_{i}-Q_{i}\right)$, where $p$ is the equilibrium permit price and $q_{i}$ the quantity of permits the emitter applies to its own emissions. A carbon tax is similar, but $q_{i}$ is the level of emissions the emitter reports as its tax base, $p$ is the tax, and $Q_{i}=0$. The important implication is that an incentive-based policy gives the emitter choices on two margins, $e_{i}$ and $q_{i}$.

The expected penalty depends on the chance a violation is detected, $D\left(v_{i}\right)$, and the fine, $F\left(v_{i}\right)$, each of which is in general a function of the magnitude of the violation $v_{i}$. For either emissions trading or a carbon tax, the violation is $v_{i}=e_{i}-q_{i}$, the difference between actual emissions and $q_{i}$.

In addition to a fine, most policies require that the violator "fix" the violation. This requirement attempts to reduce the probability that violating the law is the least cost option. Emission trading systems often implement this requirement by having violators surrender enough allowances to cover their emissions, perhaps withholding them from the violator's next-year allocation. Thus, the penalty is the fine plus the value of permits surrendered: $F\left(e_{i}-q_{i}\right)+p \times\left(e_{i}-q_{i}\right)$ (ignoring discounting if permits are surrendered next year). This penalty is multiplied by the chance the violation is detected, $D\left(e_{i}-q_{i}\right)$ to form the expected penalty.

Thus, the emitter's problem is to minimize total expected cost subject to the constraint that the

\footnotetext{
${ }^{2}$ Polluters may be risk averse, which would tend to strengthen the incentives for compliance, but not fundamentally change the problem. Malik (1990) models emission-market enforcement with risk averse polluters.
} 
violation is non-negative:

$$
\begin{array}{ll}
\min _{e_{i}, q_{i}} & c\left(e_{i}, \gamma_{i}\right)+p \times\left(q_{i}-Q_{i}\right)+D\left(e_{i}-q_{i}\right)\left[F\left(e_{i}-q_{i}\right)+p \times\left(e_{i}-q_{i}\right)\right] \\
\text { s. t. } & e_{i}-q_{i} \geq 0
\end{array}
$$

The first-order condition with respect to $q_{i}$ is important to the analysis below. If $\lambda_{i}$ is the shadow value of the constraint that the violation is non-negative for source $i$, this condition is

$$
p-\left[D^{\prime}\left(v_{i}\right)\left(F\left(v_{i}\right)+p \times v_{i}\right)+D\left(v_{i}\right)\left(F^{\prime}\left(v_{i}\right)+p\right)\right]+\lambda_{i}=0 .
$$

If $e_{i}-q_{i}$ is strictly positive (i.e., the emission source does not fully comply), then $\lambda_{i}=0$. The term in brackets is the marginal expected penalty. Thus, equation (2) implies that a partiallycompliant emitter sets its marginal expected penalty equal to the price. For an emitter to consider full compliance, the price must be less than the marginal expected penalty (since $\lambda_{i}>0$ ).

To simplify this equation for applications below, assume that the probability of detection is constant and equal to $d$ (so $D^{\prime}\left(v_{i}\right)=0$ ). In addition, assume the fine is just a fixed amount per unit of violation, so $F^{\prime}\left(v_{i}\right)=f$. This sort of fine is used in several emissions trading systems (see Table 1). Thus, the first-order condition (2) becomes

$$
p+\lambda_{i}=d \times(f+p) .
$$

\subsection{The government's choices}

The government has some control over both $d$ and $f$, but its control is incomplete. The probability of detection, $d$, does depend in part on the level and distribution of public monitoring resources. Nongovernmental forces may also be important to $d$. Whistle-blowers, often employees of noncompliant firms, account for a high share of substantive environmental violations detected (Heyes 
and Kapur, 2009). In addition, non-profit environmental organizations play a substantial role in detecting violations of current environmental laws (Thompson, 2000). ${ }^{3}$

The government also has some control over the penalty, $f$. The government can assure complete compliance with a sufficiently high expected penalty. As Becker (1968) famously argued, high fines can substitute for costly monitoring in raising the expected penalty. However, high fines are rarely used in practice. The reasons may include horizontal equity concerns and judgmentproof problems (firms cannot be fined more than the depth of their pockets). The government may face political obstacles to imposing draconian fines. Finally, high fines may trigger costly litigation, as violators have incentives to spend more to fight them.

In an emission trading system, non-draconian fines can play the role of a "safety valve," allowing polluters to avoid buying permits during price spikes and thus effectively setting a marginal cost ceiling on carbon reductions (Montero, 2002; Kruger and Pizer, 2004). However, a requirement that facilities forfeit missing allowances discourages the use of fines a safety valve. To use fines as a safety valve, the government might eliminate this requirement or allow the emitter to delay forfeiting allowances until allowance prices fall.

A Beckerian high-fine regime could also produce a low expected marginal penalty that could act as a safety valve if the government chooses a low enough $d$. In such a regime, polluters would not disclose their violations and would face a small risk of high fines. Although it would lower the government's enforcement costs, such a regime would be less transparent than a fine set as an explicit safety valve.

\subsection{Penalties and compliance in practice}

Fines in emission trading programs have mostly been modest in practice. Table 1 presents a summary of fines in the EU Emission Trading System (EU ETS) and the U.S. Acid Rain Program, with

\footnotetext{
${ }^{3}$ Both of these forms of private enforcement are likely to result in a probability of detection that rises with the violation and thus a higher marginal expected penalty than assumed in the simplified condition in equation (3).
} 
Table 1: Penalties with comparison to allowances prices

\begin{tabular}{lcccc}
\hline \hline \multirow{2}{*}{ Program } & Fine & Forfeit & \multicolumn{2}{c}{ Allowance price } \\
next period? & Average & Maximum \\
\hline EU ETS, 2005-07 & $€ 40$ & Yes & $€ 18$ & $€ 30$ \\
EU ETS, 2008-12 & $€ 100$ & Yes & $€ 17$ & $€ 29$ \\
US SO $_{2}$ allowance program (in 2008) & $\$ 3,337$ & Yes & $\$ 380$ & $\$ 550$ \\
\hline \hline
\end{tabular}

Notes: EU ETS prices calculated from BlueNext are for 2006 (first trading period) and for 2008-2009 (second trading period). The $\mathrm{SO}_{2}$ fine is adjusted for inflation, from a base of $\$ 2000$ in 1990 dollars. $\mathrm{SO}_{2}$ prices in the table are approximate.

price information for scale.

Compliance with emission trading systems seems to have been high. ${ }^{4}$ The UK reports no detected violations of the EU ETS from 2006 through 2008 and 99.7\% compliance in 2005 (U.K. Department of Energy, 2009). Landgrebe (2009) suggests the following numbers of German facilities with some sort of violation, relative to a total of 1,665 facilities issued allowances: 2005, 174 installations; 2006, 28 installations; 2007, 20 installations. Kruger and Egenhofer (2006) report only 21 excess emissions penalties under the US $\mathrm{SO}_{2}$ Allowance program in its first ten years. ${ }^{5}$

High compliance rates are something of a puzzle because of the low level of fines. To assure complete compliance, the first order condition (2) implies that the marginal expected penalty must exceed the price. With the simplifying assumptions behind equation (3), full compliance requires $p<d \times(f+p)$. For the first trading period of the EU ETS, the penalty for a violation was $€ 40$. Therefore, if we believe compliance was in fact virtually complete, detection rates had to be greater than $d=\frac{18}{40+18}$ or $31 \%$, at the average price of $€ 18$. At the peak price of $€ 30$, they had to exceed

\footnotetext{
${ }^{4}$ Two frauds recently perpetrated on the EU ETS are exceptions. One scam exploited cross-border collection of the EU VAT; the perpetrators purchased allowances without paying the VAT and then resold them, claiming to collect tax they actually pocketed (Europol, 2009). A "phishing" scam also targeted the EU ETS (Kanter, 2010). However, neither fraud seems to reveal a enforcement problem specific to climate policy.

${ }^{5}$ RECLAIM is an exception to the high compliance rates with $85-95 \%$ compliance in early years. Stranlund et al. (2002) attribute the lower compliance to penalties that are less automatic and to higher prices relative to penalties.
} 
$43 \%$. The necessary probabilities would have declined with the higher penalties in the second period, but would still have been high. ${ }^{6}$

The perceived chance of detection seems unlikely to be so high, particularly for small violations. ${ }^{7}$ Perhaps widespread violations do occur, but are not detected. More likely, firms expect costs from noncompliance other than the official fines, so the calculations above understate the private costs of noncompliance. Noncompliance may tarnish the firm's image with its consumers, host community, potential employees, and regulators. These concerns may loom especially large in a carbon market with on-going government allocation of valuable allowances: the participants may worry that current noncompliance will lower their future allowance allocations.

If firms perceive a large informal penalty, full compliance requires a lower risk of detection, $d$, than it would have required with official fines only. The possibility of substantial informal penalties has two policy implications. First, if the government faces constraints on the magnitude of official fines, it might try to raise informal penalties. For example, press releases with the names of violators might draw attention, lowering the required $d$ and thus the government's enforcement costs. Second, high informal penalties make it difficult for the government to use fines as a safety valve. Even if the official fines are low enough to provide a safety valve at a relevant price level, firms may still have strong incentives to comply because of these other costs of violation.

\section{Heterogeneous monitoring costs}

Relative to the enforcement problems that have been studied previously, carbon markets add the complication of especially heterogeneous monitoring costs. Because such heterogeneous costs may raise novel issues for policy design, this section presents information on the cost differential for market participants. Information on costs for public enforcement agencies is not available but

\footnotetext{
${ }^{6}$ Stranlund et al. (2002) conduct similar calculations of required detection rates for the $\mathrm{SO}_{2}$ Allowance program.

${ }^{7}$ Perceived chances of detection may dramatically overstate the reality. Research on income tax compliance shows households consistently overestimate their risk of an audit (Andreoni et al., 1998). However, the large firms involved in carbon emissions are likely to be more savvy about actual monitoring systems and detection risks.
} 
likely shows the same sort of variation as private monitoring costs.

\subsection{Direct costs of monitoring}

Large facilities that emit carbon dioxide probably do not face high costs when trying to demonstrate compliance. They may calculate carbon emissions using mass-balance approaches or may use continuous emissions monitoring $(\mathrm{CEM}){ }^{8}$ The EU ETS allows emissions to be calculated from inputs and production technology for many sources (EC, 2007). In the US, a number of firms already have installed CEM for $\mathrm{CO}_{2}$ (Kruger and Engenhofer, 2006). The possibility of good mass-balance estimates of $\mathrm{CO}_{2}$ emissions from point sources is likely to keep the government's enforcement task manageable for these sources.

The EU ETS requires third-party verification of emissions from facilities subject to its controls. This approach partially privatizes enforcement and creates a system analogous to the verification system for offsets. A verification market participant reports that "verification costs ranged from $€ 5,000$ - $€ 7,500 \ldots$ for a simple site to $€ 10,000$ - $€ 20,000 \ldots$ or more for a more complex site" (Kruger and Pizer, 2004, p. 19) in the voluntary UK Emissions Trading Scheme, which ran from 2002 to 2006. Third-party verification probably raises social costs by less than this amount, however, because verification substitutes for public monitoring and for activities the source might have conducted internally.

A survey by Jaraite et al. (2009) of Irish firms in the EU ETS first trading period provides data on overall private monitoring costs. It finds that "monitoring, reporting and verification" (MRV) costs averaged $€ 0.04$ per ton of $\mathrm{CO}_{2}$ or about $€ 25,000$ per year per respondent. Thus, monitoring costs averaged only about $0.1 \%$ of the total compliance costs, if we assume average compliance

\footnotetext{
${ }^{8}$ The US SO$~_{2}$ Allowance program requires CEM for large sources, although facilities could probably have calculated emissions with fairly high precision. Ellerman et al. (2000) find that CEM has been costly, contributing to private monitoring costs equal to $7 \%$ of total compliance costs. However, they argue that this approach has the advantage of separating true compliance activities from monitoring and helped convince skeptics of the environmental effectiveness of tradable permit programs.
} 
costs are a quarter of marginal costs (the allowance price). ${ }^{9}$ Jaraite et al. also report that $40 \%$ of MRV costs are for external consultants, which confirms the market participant report from Kruger and Pizer (2004).

Private monitoring and verification costs for other sources, such as those proposed as the basis for offsets, are probably much higher for several reasons. The emissions may not be from point sources, ruling out continuous emissions monitoring and requiring more complicated information. The burden of establishing "additionality" (reductions relative to some meaningful baseline) also may fall on originators of offsets. Finally, the relevant activities may take place abroad and possibly in countries with more corruption, adding to the complexity of assuring compliance.

Antinori and Sathaye (2007) provide an estimate of monitoring and verification costs for offsets. The 28 greenhouse-gas emissions reductions projects that they study report average monitoring and verifications costs of $\$ 0.30$ per metric ton of $\mathrm{CO}_{2}$, although the variance is high and a few large projects report much lower costs. ${ }^{10}$ Compared with the average monitoring costs of $€ 0.04$ (about $\$ 0.06$ ) per ton of $\mathrm{CO}_{2}$ for covered facilities in Jaraite et al. (2009), these estimates suggest monitoring costs may be several times higher for offsets.

\subsection{Differential enforcement risks}

Higher monitoring costs probably reduce private monitoring. With less thorough monitoring, allowances may be subject to greater risk that the government will find them invalid and conclude that the emitter is out of compliance. The variation in private monitoring costs shown above thus may lead to variation in what I will call the "validity" of the allowance: the chance that the emitter

\footnotetext{
${ }^{9}$ Ellerman et al. (2010) report a lack of ex post estimates of the total costs of the EU ETS first trading period and assume the average costs are half the marginal costs (a linear cost curve).

${ }^{10}$ Alternatively, one can estimate the costs of monitoring offsets by comparing prices for emissions reductions with more rigorous and less rigorous certification. Conte and Kotchen (2009) analyze carbon offset prices from an online listing in 2007, $13 \%$ of which have the more rigorous certification that would make them eligible for use in compliance with Kyoto obligations and the EU ETS. They estimate that certified permits cost $30 \%$ more than other projects with similar observable characteristics. Although many demand and supply factors may underlie this price differential, the costs of the certification probably contribute part of it. If even $10 \%$ of Conte and Kotchen's low-end estimate of a $30 \%$ price difference is monitoring costs, these costs are $\$ 0.54$ per ton of $\mathrm{CO}_{2}$.
} 
is deemed to be in compliance when using that allowance. Market prices may reflect any differences in validity across different sorts of allowances and, thus, provide indirect evidence of differential monitoring costs.

Figure 1 presents the history of the premium between two types of allowances in Europe. Facilities subject to EU ETS restrictions may cover their emissions either with the European Union Allowances (EUAs), which the EU issues to point sources of $\mathrm{CO}_{2}$, or with Certified Emissions Reductions (CERs). CERs result from greenhouse gas emission reduction projects undertaken through the Kyoto Protocol's Joint Implementation (JI) or Clean Development Mechanism (CDM). ${ }^{11}$

The figure compares spot market prices of EUAs and "secondary" CERs on one of the major exchanges, BlueNext. " "Secondary" CERs are being resold, as opposed to "primary" CERs sold by the originating project. The average price differential between EUAs and CERs from August 2008 through February 2010 is $€ 1.64$; the maximum of $€ 5.03$ occurred early in the period when allowance prices were highest.

We would expect EUAs and CERs to be perfect substitutes for complying EU facilities; thus the existence of a price difference requires explanation. ${ }^{13}$ One possibility is that the public relations consequences of using EUA and CERs differ, even if the two types of allowances are equally valid from an enforcement perspective. The public may view CERs less favorably than EUAs because CERs relax the constraint that Europe has put upon its own carbon dioxide emissions. However, the public also might prefer CERs to EUAs as "charismatic carbon"; CERs may promise nonclimate benefits, such as reducing local air pollution or protecting natural ecosystems. A second possibility is that market participants perceive a greater risk of being found out of compliance with CERs than with EUAs. The price differential then measures the disparity in the expected validity

\footnotetext{
${ }^{11}$ The vast majority of CERs originate in China and derive from hydroelectric and wind projects (Capoor and Ambrosi, 2009).

${ }^{12}$ Mizrach (2009) discusses the exchanges and analyzes various spot and futures prices in international carbon markets, including the EUA-CER spread.

${ }^{13}$ The EU ETS does place caps on the number of CERs each country may use cumulatively over the second trading period. However, this country-level constraint does not affect an individual source's current ability to substitute freely between the two types of allowance and thus does not imply different current spot prices.
} 


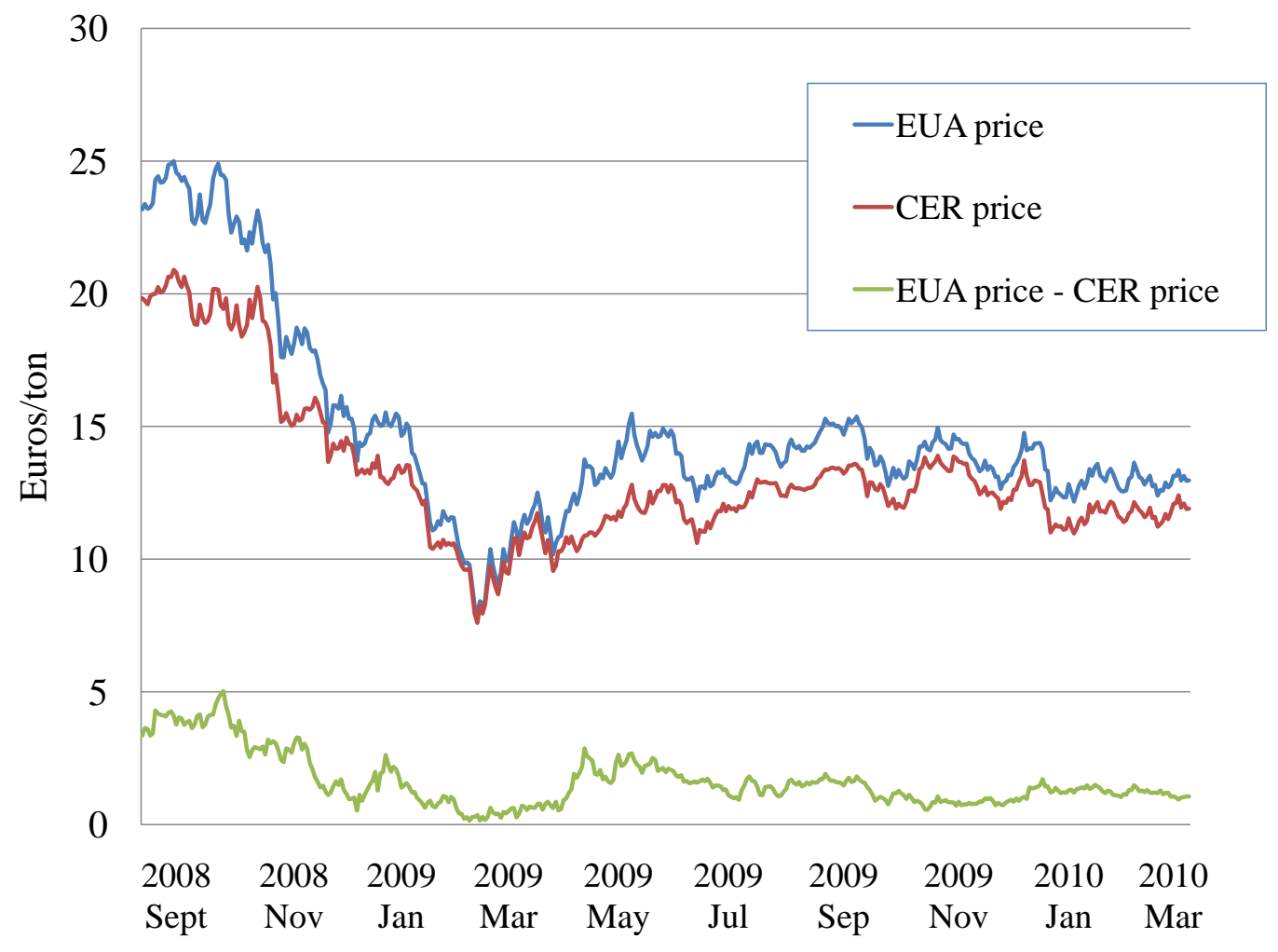

Source: BlueNext (www.bluenext.fr)

Figure 1: Spot prices of EUAs and secondary CERs and their difference 
of the two types of allowances.

Suppose the risk that the government finds a violation is $d_{E U A}$ for EUAs and $d_{C E R}$ for CERs. The penalty is the same with either type of permit because it consists of a fine and forfeit of EUAs from next year's allocation. Using the simplified first order condition in equation (3), the difference in the marginal expected penalties and thus the price premium is $p_{E U A}-p_{C E R}=\left(d_{E U A}-d_{C E R}\right) \times$ $\left(f+p_{E U A}\right)$. With the official fine of $f=€ 100$, an average EUA price of $€ 25$ over the period of price premium data, and an average premium of $€ 1.64$, the detection probabilities would differ by 1.3 percentage points, a modest amount.

However, a major objection to this calculation is that the EU ETS places liability for compliance on sellers. Thus, the buyer of CERs might not believe it faced any higher expected penalty than if it had purchased EUAs. On the other hand, public opinion may not respect the legal allocation of compliance obligations, so a violation may still have public relations costs for the buyer. Depending on the comparison between the marginal public-relations cost and the official fine, the 1.3 percentage point disparity may be either too high or too low.

\subsection{Policy design with heterogeneous enforcement costs}

The variation in monitoring costs across different sources of allowances (e.g., the EUA-CER differential) and the resulting differences in validity produce a number of issues for policy design. A question for US climate policy is whether evidence of very high monitoring and enforcement costs for some sources of allowances is a reason to exclude them from the market. For example, a policy might allow only domestic offsets or no offsets at all.

The simple enforcement model above suggests, however, that even with a fixed enforcement budget, broadening the program might not reduce the compliance rate. ${ }^{14}$ Compliance could increase, even as fixed enforcement resources are spread more broadly, because the allowance price determines incentives for noncompliance. Expanding the possible sources of allowances brings

\footnotetext{
${ }^{14}$ Sigman and Chang (2010) provide a formal model of offsets with imperfect enforcement.
} 
additional low cost sources of greenhouse gas abatement into the market, lowering the price of allowances. This reduction in price means that the marginal expected penalty required for full compliance falls and thus a lower detection rate can sustain full compliance.

Consider a broadening of the market that causes the allowance price to fall from $p$ to $\delta p$. Using equation (3), the probability of detection required for full compliance falls from $d_{0}=\frac{p}{f+p}$ to $d_{1}=\frac{\delta p}{f+\delta p}$. For example, US EPA (2009) estimates that elimination of international offsets would nearly double the allowance price (from $\$ 13-\$ 17$ to $\$ 25-\$ 33$ in 2015 ; from $\$ 17-\$ 22$ to $\$ 33-\$ 44$ in 2020) for the Waxman-Markey bill. If the fine were set at five times the initial allowance price (along the lines of the EU ETS), including the international allowances would allow the $d$ required for full compliance to fall to $55 \%$ of the $d$ in the narrower market. ${ }^{15}$ Thus, a fixed government enforcement budget might go farther. The net effect on compliance depends upon the relationship between government outlays and $d$ in the narrower and broader markets. Nonetheless, this change in the required detection rate does suggest one cannot rule out broader markets on enforcement grounds without further scrutiny. ${ }^{16}$

\section{Conclusions}

A climate policy that controls domestic $\mathrm{CO}_{2}$ emissions from fossil fuels may not present too great an enforcement challenge. Experiences with the EU ETS and the U.S. $\mathrm{SO}_{2}$ trading program suggest a high degree of compliance with emission trading, despite non-draconian penalties. High compliance may partly result from public relations costs for violators.

Previous experience does suggest that monitoring costs vary substantially across different types

\footnotetext{
${ }^{15}$ This example illustrates possible magnitudes only. The actual Waxman-Markey legislation sets the excess emission fine at twice the allowance price (H.R. 2454, 111th Congress, Section 723). This rule would reduce compliance incentives along with compliance costs and not give rise to the effect in the text.

${ }^{16}$ This analysis takes a narrow view of "compliance" for offsets, considering only whether actions promised are undertaken, not whether they contribute to an overall reduction in atmospheric greenhouse gases. Elsewhere in this volume, Bushnell (2010) and Borenstein (2010) consider broader issues in expanding the sources of greenhouse gas abatement.
} 
of allowances in current markets. This variation raises some interesting questions for future analysis. For example, it would be useful to study whether enforcement agencies could improve the overall efficiency of the program by narrowing the difference in the validity of allowances from different sources.

A policy response to the variation in enforcement costs could be to restrict the market to areas of low enforcement cost. However, the simple model presented here suggests that broader markets may not lower compliance if they allow lower allowance prices. This analysis shows the importance of recognizing that enforcement strategies can respond to market conditions and that market conditions may be sensitive to these strategies. Both aspects of this relationship deserve additional study. 


\section{References}

Andreoni, James, Brian Erard, and Jonathan Feinstein. 1998. Tax compliance. Journal of Economic Literature 36 (2): 818-60.

Antinori, Camille and Jayant Sathaye. 2007. Assessing transaction costs of project-based greenhouse gas emissions trading. Berkeley, CA: Lawrence Berkeley National Laboratory Report 57315.

Becker, Gary S. 1968. Crime and punishment: An economic approach. The Journal of Political Economy 76 (2): 169-217.

Borenstein, Severin. 2010. Markets for anthropogenic carbon within the larger carbon cycle. This volume.

Bushnell, James B. 2010. The economics of carbon offsets. This volume.

Capoor, Karan and Philippe Ambrosi. 2009. State and trends of the carbon market, 2009, Washington, DC: The World Bank.

Conte, Marc N., and Matthew J. Kotchen. 2009. Explaining the price of voluntary carbon offsets. National Bureau of Economic Research, Inc, NBER Working Papers: 15294.

Ellerman, A. Denny, Paul Joskow, Richard Schmalensee, Juan-Pablo Montero, and Elizabeth Bailey. 2000. Markets for clean air: The U.S. Acid Rain Program. Cambridge UK: Cambridge University Press.

Ellerman, A. Denny, Frank J. Convery, and Christian De Perthuis. 2010. Pricing carbon: The European Union emissions trading scheme. Cambridge UK: Cambridge University Press.

European Commission. 2007. 2007/589/EC: Commission Decision of 18 July 2007 establishing guidelines for the monitoring and reporting of greenhouse gas emissions. http://eur-lex.europa.eu/LexUriServ/LexUriServ.do?uri=OJ:L:2007:229:0001:0085:EN:PDF

Europol. 2009. Carbon credit fraud causes more than 5 billion euros damage for European taxpayer. http://www.europol.europa.eu/index.asp?page=news\&news=pr091209.htm (December 9, 2009)

Harford, Jon D. 1978. Firm behavior under imperfectly enforceable pollution standards and taxes. Journal of Environmental Economics and Management 5 (1): 26-43.

Heyes, Anthony and Sandeep Kapur. 2009. An economic model of whistle-blower policy. Journal of Law, Economics, and Organization 25 (1): 157-82.

Jaraite, Jurate, Frank Convery, and Corrado Di Maria. 2009. Assessing the transaction costs of firms in the EU ETS: Lessons from Ireland. SSRN eLibrary. http://ssrn.com/abstract=1435808. 
Johnstone, Nick. 2005. Tradable permits for climate change: Implications for compliance, monitoring, and enforcement. In Climate-change policy, ed. Dieter Helm, 238-252. Oxford, UK: Oxford University Press.

Kanter, James. 2010. Hackers hit Europe's carbon market. The New York Times February 4, 2010.

Kruger, Joe and Christian Egenhofer. 2006. Confidence through compliance in emissions trading markets. Sustainable Development Law and Policy 6 (2): 2-14.

Landgrebe, Jurgen. 2009. Verification in the EU ETS: German perspective. Presentation at ICAP China Conference, October 12-13, 2009. http://www.icapcarbonaction.com/phocadownload/china_conference/Presentations191009/icap_china_conf_plenary4_landgrebe.pdf

Malik, Arun S. 1990. Markets for pollution control when firms are noncompliant. Journal of Environmental Economics and Management 18 (2): 97-106.

Mizrach, Bruce. 2009. Integration of the global emissions trading markets. Rutgers University, Department of Economics Working Paper 2009-1.

Montero, Juan-Pablo. 2002. Prices versus quantities with incomplete enforcement. Journal of Public Economics 85 (3): 435-54.

Pizer, William, and Joseph Kruger. 2005. The EU emissions trading directive: Opportunities and potential pitfalls. Resources For the Future, Discussion Papers.

Sigman, Hilary and Howard F. Chang. 2010. The Effect of Allowing Pollution Offsets with Imperfect Enforcement. University of Pennsylvania Working Paper.

Stranlund, John K., Carlos A. Chavez, and Barry C. Field. 2002. Enforcing emissions trading programs: Theory, practice, and performance. Policy Studies Journal 30 (3): 343-361.

Stranlund, John K., and Kanwalroop Kathy Dhanda. 1999. Endogenous monitoring and enforcement of a transferable emissions permit system. Journal of Environmental Economics and Management 38 (3): 267-82.

Thompson, Barton H. Jr. 2000. The continuing innovation of citizen enforcement. University of Illinois Law Review:185-236.

UK Department of Energy and Climate Change. 2009. Report on 2008 EU Emissions Trading System emissions data.

US Environmental Protection Agency. 2009. EPA analysis of the Waxman-Markey discussion draft: The American Clean Energy and Security Act of 2009. http://www.epa.gov/climatechange/economics/economicanalyses.html. 